\title{
Correlation analysis between starch properties and single nucleotide polymorphisms of waxy genes in common rye (Secale cereale $\mathrm{L}$. )
}

\author{
M. Meng ${ }^{1}$, X. Gao ${ }^{1,2}$, L.J. Han ${ }^{1}$, X.Y. Li ${ }^{1,2}$, D. Wu ${ }^{1}$, H.Z. Li ${ }^{1}$ and Q.J. Chen ${ }^{1,2}$ \\ ${ }^{1}$ College of Agronomy, Northwest A\&F University, Yangling, China \\ ${ }^{2}$ Wheat Engineering Research Center of Shaanxi Province, Shaanxi, China \\ Corresponding authors: X. Gao / Q.J. Chen \\ E-mail: gx@nwsuaf.edu.cn / qjchen@nwsuaf.edu.cn
}

Genet. Mol. Res. 13 (2): 2574-2589 (2014)

Received June 28, 2013

Accepted October 23, 2013

Published January 14, 2014

DOI http://dx.doi.org/10.4238/2014.January.14.7

\begin{abstract}
To understand the relationships between single nucleotide polymorphisms (SNPs) in the waxy gene and starch parameters in common rye, we performed sequence characterization, enzyme activity testing, amylopectin/amylose ratio evaluation, starch property testing, and correlation analysis. Specific primers were used to clone waxy from 20 rye cultivars. Sequence analysis showed that waxy was $2852 \mathrm{bp}$, including 11 exons, and sequence similarity across the 20 cultivars was over $98 \%$. The Waxy protein showed $>95 \%$ similarity with those from wheat, rice, and barley, the closest genetic relationship being with wheat Wx-A type. Waxy had multiple SNPs, most of which were located in the exons. Amino acid variants were found to be mainly distributed in the catalytic domain in an imbalanced state. Multi-factor correlation analysis revealed significant correlation among starch pasting parameters in rye flour. The Waxy protein activity was significantly negatively correlated with the amylose content and amylopectin/amylose ratio. However, pasting parameters, Waxy
\end{abstract}


enzyme activity, and amylopectin/amylose content ratio were not correlated. The correlation of SNPs, the key catalytic site of Waxy, with starch parameters and enzyme activity suggested that both starch pasting parameters and Waxy protein activity were influenced by No. 260 amino acid (aa). Further, the 141 and 152 aa loci were found in the enzymecatalyzing domain of Waxy. Interestingly, Waxy enzyme activity was also influenced by the 363 aa locus in the pliable region. These results provide important theoretical regarding the high-throughput quality identification of noodle starch, functional studies, directional selection, and molecular markers of wheat Wx subunits.

Key words: Secale cereale L.; Waxy protein; SNPs; Starch quality; Correlation analysis

\section{INTRODUCTION}

Common rye (Secale cereale $\mathrm{L}$. $\operatorname{ssp}$ cereale, $2 \mathrm{n}=2 \mathrm{x}=14, \mathrm{RR}$ ) is a major crop in many areas of northern and eastern Europe owing to its considerable winter hardiness. Although, on a global scale, its production is about $5 \%$ of that of wheat or rice, in areas with extreme climatic and poor soil conditions, rye may still occupy up to $30 \%$ of the acreage (Madej, 1996; Chebotar et al., 2003). The main advantages of rye over other winter cereals are its excellent resistance to many kinds of diseases such as rust, powdery mildew, tilletia, and barley yellow dwarf virus; superior tolerance to low temperatures or other stress condition; and its ability to realize relatively high grain yields even under an infertile environment (Chebotar et al., 2003). Therefore, rye could provide wheat breeders with an excellent source of biotic and abiotic stress tolerances (Javed-Iqbal and Lane-Rayburn, 1994; Bushuk, 2001).

As the major reserve of carbon and energy in cereal crops, starch accounts for approximately 50 to $70 \%$ of dry matter between cereal grain seeds, including wheat, barley, and rye (Emes et al., 2003). In general, this kind of biopolymer could be divided into branched molecule glucose polymer (called amylopectin, Ap) and linear or slightly branched molecule glucose polymer (called amylose, Am; Ghiasi et al., 1984; Hannah and James, 2008; Carciofi et al., 2012). Because of its ability to combine with gluten, together with its special physicochemical properties and temperature-dependent interactions with water during gelatinization, pasting, and gelation, starch plays very complicated role during baking performance, mouthfeel properties, and others processes (Zeng et al., 1997; Ragaee and Abdel-Aal, 2006). To date, the pasting properties are adopted as an important index of starch quality with close relationship to the quality of noodles, breads, and other cereal-based food (Tetlow et al., 2004; Ragaee and Abdel-Aal, 2006). Cereal starch was synthesized through a series of common biochemical reactions, i.e., the formation of ADP-glucose by ADP-glucose pyrophosphorylase (AGP), and its subsequent conversion into insoluble glucans by starch synthases (SS) and starch branching enzymes (SBE; James et al., 2003). During the conversion process of ADP-glucose to starch polymers in cereal seeds, the granule-bound starch synthase (GBSSI, also known as Waxy or Wx enzyme) are thought to play a vital role in the synthesis of amylose and building of the final structure of amylopectin (Mérida et al., 1999; Huang and Brûlé-Babel, 2010). Thus far, the coding sequences of Waxy have been isolated and characterized from many species, including wheat (Murai et al., 1999), rice (Wang et al., 1990), barley (Rohde et al., 1988), and corn (Klosgen et al., 1986). In common wheat 
(Triticum aestivum L.), 3 homeologous genes, $W x-A 1, W x-B 1$, and $W x-D 1$, were further located on 7AS, 4AL, and 7DS, respectively (Yamamori and Quynh, 2000). Results showed that Waxy mutation would definitely influence the amylose content in the endosperm. Subsequent analysis revealed that the quality of flour was directly controlled by the amylose content (Ragaee and Abdel-Aal, 2006). Correlation between protein and amylose has been thoroughly explored. The number of Waxy subunits in wheat endosperm has significant influence on the contents of Waxy protein and amylose. Some studies revealed that, with an increase in Waxy subunit number, the swelling power presented a decline trend, whereas amylose content and peak viscosity showed the opposite trends (Song et al., 2004). Diversity of the waxy gene has also been widely reported. Several different results indicated that the G-T polymorphism and (CT)n polymorphism in the rice waxy gene have a certain correlation with the amylose content (Vrinten et al., 1999; van de Wal et al., 2001; Chen, 2010). Chen (2010) indicated that this might account for the 72.4-91.2\% difference in the amylose content of rice varieties. However, studies on starch synthase and properties of rye are few. Schierbaum et al. (1991) and Weipert (1997) reported the good quality properties of rye due to its higher xylitol but lower pasting temperature than that of wheat. Rye starch was extracted by Verwimp et al. (2004) and Wang and Wang (2001) by using different methods. Few records of rye waxy gene sequences could be obtained from GenBank. The cDNA sequence of rye was obtained by Xu et al. (2009), and the structural domain of the waxy gene in rye and the corresponding GBSSI protein were described briefly. Besides, phylogenetic relationships based on genomic GBSSI between rye and other plants were also reported.

A rapid visco analysis (RVA) system could be used to study the pasting properties of wheat flours according to the parameters of peak viscosity, breakdown, final viscosity, and setback on the RVA curve (Cozzolino et al., 2013). These data on the curve usually are served as the direct index of flour (e.g., lower final viscosity and negative setback are often associated with lower apparent and total amylose contents) and even as determination of the characteristics of the material and its end-use in wheat (Ragaee and Abdel-Aal, 2006; Cozzolino et al., 2013). Association analysis could be used to identify candidate single nucleotide polymorphisms (SNPs) from the target genes that related to some traits. This approach suggested that TaSAP1-A1 and 4 SNPs in HSP17.8 were significantly associated with 1000-grain weight, number of grains per spike, spike length, and other important agronomic traits in wheat and barley, respectively (Chang et al., 2013; Xia et al., 2013).

The properties of diploid rye and its partial homologous relationship with wheat and thorough exploration of the properties of starch and Waxy protein in germplasm resources of rye could be useful for the selection and breeding of wheat varieties. However, to date, few studies have focused on the diversity of the rye waxy gene and the relationships among starch properties, Waxy activities, and SNPs of Waxy. The objectives of the present study were to (1) obtain the full length of waxy encoding region from 20 rye accessions by using the primers developed based on the homologous sequences of wheat; (2) measure the enzyme activity, starch content, and RVA parameters of the 20 samples; and (3) analyze the correlations among amylopectin/amylose content ratio, pasting parameters, Waxy enzyme activity, and corresponding SNPs with this gene.

\section{MATERIAL AND METHODS}

\section{Materials}

Twenty rye varieties for the experiment were all preserved by the Yangling Branch of 
China National Wheat Improvement Centre. The materials were planted in the experimental field in 2011, and the conventional management regime was employed. The young leaves were selected for DNA extraction in March 2012. Grain seeds were harvested in June 2012 and were subsequently ripened for 1 week after threshing. Flour was milled through a 100mesh sieve (Brabender Farinograph), and then used for amylopectin and amylose content determination after 2 weeks. Plump seeds were selected for testing the activity of Waxy protein enzyme. All indices were tested in replicate.

Escherichia coli DH5 $\alpha$, pMD18-T vector, LA Taq DNA polymerase, and T4 DNA ligase were purchased from TaKaRa Company (Dalian); 2x EcoTaq mix was from Beijing TransGen Biotech Co. Ltd.; IPTG was from Solarbio Company; and DNA gel recovery and purification reagent kit was from Tiangen Biotec Co. Ltd. (Beijing). The amylopectin, pyruvate kinase, hexokinase, and G6-dehydrogenase (NADP) were purchased from Sangon Company. Unless otherwise specified, all drugs and reagents for this experiment were analytically pure, and the water was ultrapure.

\section{Cloning of waxy genes}

The complete coding sequences of common wheat varieties present in the database, including AF163319 and EU719608, were surveyed for determining the WxF0/WxR2800 primer combination that could cover the total length (WxF0: 5'-ATGGCGGCTCTGGTCACGT-3', WxR2800: 5'-TCAGGGAGCGGCGACGTT-3'). Primers were synthesized using GenScript (Nanjing) Co. Ltd. Total genomic DNA was extracted using the micro-CTAB extraction method. Reaction system for PCR amplification of the coding genes consisted of $100 \mathrm{ng}$ template DNA, $1 \mu \mathrm{L}$ of each $0.1 \mu \mathrm{M} \mathrm{WxF} 0$ and $\mathrm{WxR} 2800,0.25 \mu \mathrm{L}$ LA Taq DNA polymerase, and $12.5 \mu \mathrm{L} 0.05 \mathrm{mM}$ dNTP mix. The $\mathrm{ddH}_{2} \mathrm{O}$ was added until the reaction volume reached 25 $\mu \mathrm{L}$. Conditions for PCR were as follows: predegeneration for $5 \mathrm{~min}$ at $95^{\circ} \mathrm{C}$, degeneration for $40 \mathrm{~s}$ at $94^{\circ} \mathrm{C}$, annealing and extension for $8 \mathrm{~min}$ at $68^{\circ} \mathrm{C}$, with a total of 35 cycles. Annealing was then performed for $8 \mathrm{~min}$ at $68^{\circ} \mathrm{C}$, followed by preservation at $4^{\circ} \mathrm{C}$. PCR products were tested on $1 \%$ agarose gel electrophoresis. Target segments were recovered and connected with $\mathrm{pMD} 18-\mathrm{T}$ vector overnight at $16^{\circ} \mathrm{C}$ after purity detection. The connection products were added to the $E$. coli competent DH5 $\alpha$ cells and then cultivated overnight on LB plates coated with moderate ampicillin at $37^{\circ} \mathrm{C}$. Colony PCR was performed using sequencing primer $\mathrm{M} 13 \mathrm{~F} / \mathrm{R}$. The $10 \mu \mathrm{L}$ reaction system included $1 \mu \mathrm{L}$ bacterial liquid as template, $0.5 \mu \mathrm{L}$ each $\mathrm{M} 13 \mathrm{~F} / \mathrm{R}$, and $5 \mu \mathrm{L} 2 \mathrm{x}$ EcoTaq mix. Next, $\mathrm{ddH}_{2} \mathrm{O}$ was added until the reaction volume reached $10 \mathrm{~mL}$. Reaction conditions were as follows: predegeneration for $5 \mathrm{~min}$ at $95^{\circ} \mathrm{C}$, degeneration for $40 \mathrm{~s}$ at $94^{\circ} \mathrm{C}$, annealing for $45 \mathrm{~s}$ at $58^{\circ} \mathrm{C}$, and extension for $90 \mathrm{~s}$ at $72^{\circ} \mathrm{C}$, with a total of 25 cycles. Final extension was $8 \mathrm{~min}$ at $72^{\circ} \mathrm{C}$, and then the products were preserved at $4^{\circ} \mathrm{C}$. Three independent positive clones were selected randomly and sequenced by GenScript (Nanjing) Co. Ltd.

\section{Determination of amylopectin/amylose contents}

The amylopectin/amylose contents were determined using the dual-wavelength method of Jarvis and Walker (1993). Concentration was calculated based on the amylopectin/amylose regression equation. Amylopectin/amylose contents in the sample were calculated, and the sum of the 2 was the total starch content. 


\section{Determination of GBSS activity}

The activity of GBSS was determined as per the method of Flipse (Flipse et al., 1996) by using a spectrophotometer (Thermo Spectronic UNICAM UV 300).

\section{Determination of starch viscosity coefficient}

Starch viscosity was tested using Newport Rapid Visco Analyser Super 3 (RVA), and pasting parameters were determined using Standard Method 1 and Standard Analysis Method 1 provided by Newport Scientific Ltd.

\section{Nucleic acids and protein sequence analysis}

Splicing, alignment, and translation of DNA sequences were performed using DNAMAN (ver. 6.0 DEMO). Homologous sequence search for nucleotide and amino acid sequences was carried out using NCBI BLAST (http://www.ncbi.nlm.nih.gov/BLAST). Secondary structure of proteins was predicted using the SOMP online software (http://npsa-pbil.ibcp.fr/cgi-bin/npsa_automat. $\mathrm{pl}$ ? page $=/ \mathrm{NPSA} / \mathrm{npsa}$ _sopm.html). EBI was selected to determine the similarity of the protein family (http://www.ebi.ac.uk/interpro/IProtein?ac=A2Y8X2\&query=). The tertiary structure of proteins was predicted using SWISS-MODEL (http://swissmodel. expasy.org//SWISS-MODEL. $\mathrm{html})$. RasMol2.7 was selected for the visualization of proteins. Structural domain of Waxy protein was analyzed using Motifscan (http://myhits.isb-sib.ch/cgi-bin/motif_scan), and MEGA5.0 was used for constructing the phylogenetic tree.

\section{Correlation between properties and gene SNPs}

Excel was used for statistical analysis of starch property (amylopectin, amylose contents, and pasting parameters) and enzyme activity of the flour grain, and the SPSS software was used for variance analysis. Correlation between the waxy gene, starch properties, and pasting parameters was analyzed using the TASSEL software. $\mathrm{P}<0.05$ indicated significance, and $\mathrm{P}<0.01$ extreme significant.

\section{Starch parameters analysis}

SigmaPlot 12.0 was used for determining the distribution of starch contents, pasting parameters, and Waxy activity.

\section{RESULTS}

\section{Amplification and cloning of target genes}

The genomic DNA of 20 rye samples was amplified using primer sets WxF0/ WxR2800. A single band of about 2800 bp was obtained from each material (Figure 1). Positive clones were obtained from colony PCR amplification, and 3 independent clones were selected from each variety for sequencing. Blast, alignment, and assembly methods of 
serial softwares revealed 20 ORFs, and these were submitted to the GenBank (http://www. ncbi.nlm.nih.gov/sites/entrez). The accession number is from KC572688 to KC572707 (Table 1).

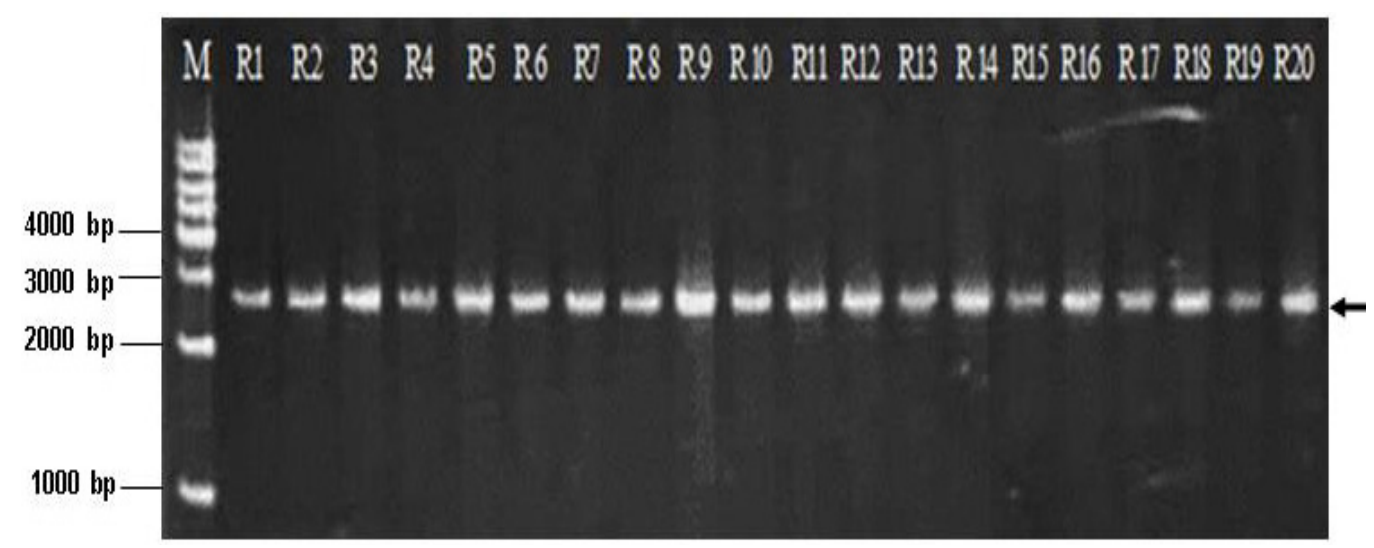

Figure 1. Amplification of waxy gene. Lane $M=$ marker trans $1 \mathrm{~kb}$, lanes $R 1-20=$ rye. Arrow points to the PCR product.

Table 1. Gene accession numbers and the corresponding wheat cultivars.

\begin{tabular}{llcc}
\hline Rye cultivar & GenBank No. & Rye cultivar & GenBank No. \\
\hline Rye05 & KC572688 & Rye15 & KC572698 \\
Rye06 & KC572689 & Rye16 & KC572699 \\
Rye07 & KC572690 & Rye17 & KC572700 \\
Rye08 & KC572691 & Rye18 & KC572701 \\
Rye09 & KC572692 & Rye19 & KC572702 \\
Rye10 & KC572693 & Rye20 & KC572703 \\
Rye11 & KC572694 & Rye01 & KC572704 \\
Rye12 & KC572695 & Rye02 & KC572705 \\
Rye13 & KC572696 & Rye03 & KC572706 \\
Rye14 & KC572697 & Rye04 & KC572707 \\
\hline
\end{tabular}

\section{Analysis of the waxy genes}

\section{Diversity analysis of the waxy gene}

The sequencing results were spliced and aligned to obtain 20 complete sequences. The online blast analysis confirmed that the tested sequences had a homology over $85 \%$ with the wheat waxy gene (accession No.: EU719608, EU719610, and EU719612) and a similarity of $95 \%$ with the waxy coding sequence of rye variety Rogo (accession No.: FJ491376). Primary structure analysis of the sequences indicated that all the cloned sequences contained 11 exons and 10 introns (Figure 2), and the encoding region was 1815 bp with a homology of $99 \%$. Therefore, the cloned sequences were all waxy gene sequences from rye. 


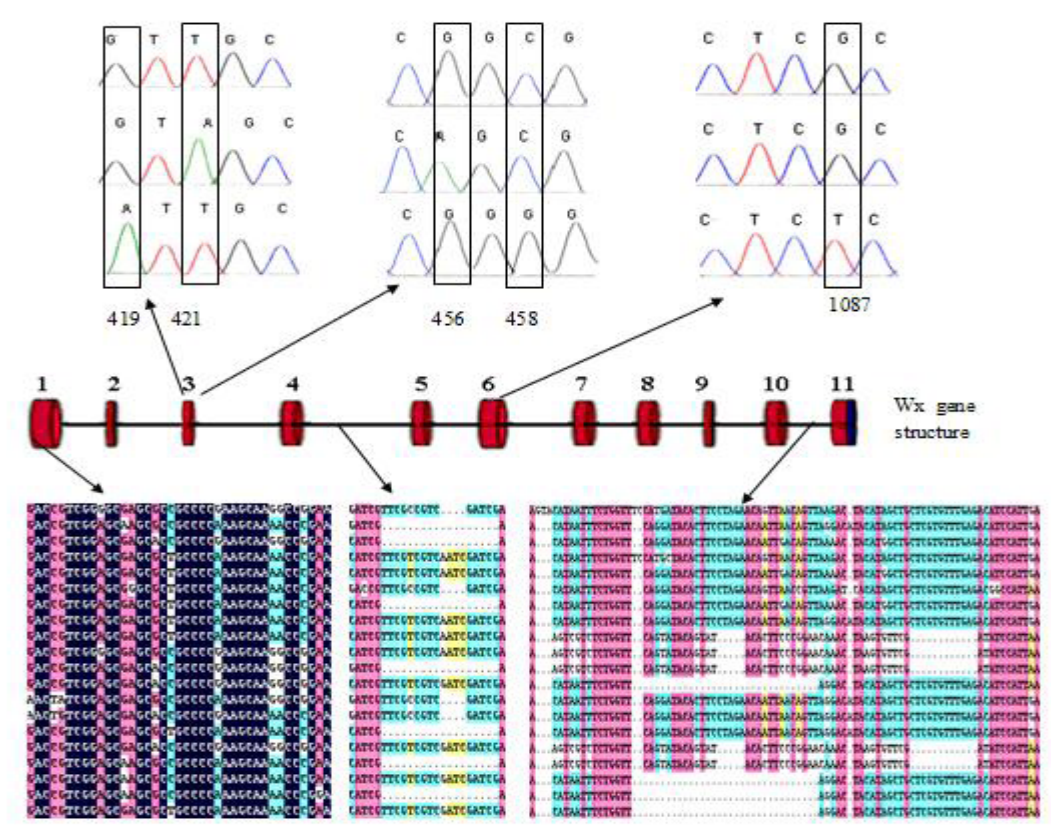

Figure 2. Basic structure of the waxy gene. Cake-shaped parts denote the exons, and the middle lines denote the introns. The peaks in the upper part indicate the allelic variations of 5 loci, namely 419, 421, 456, 458, and 1087. The lower sequence alignment reveals the variations of 1 st exon, 4th intron and 10th intron as well as the difference between them.

Nucleotide sequence alignment showed that the waxy gene in rye had a full length of $2852 \mathrm{bp}$ with an encoding region of $1815 \mathrm{bp}$. Among the 20 materials of encoding sequences, 253 SNP loci were detected, with an average of 1 SNP in every $11.27 \mathrm{bp}$. The exons contained 111 SNPs, including 49 single mutation loci, 58 loci of base mutation in 2 consecutive loci, and 4 loci of base mutation in 3 consecutive loci. For all encoded amino acids, 33 were meaningful mutations. All the exons of 20 materials contained SNPs and no insertion/deletion mutation. The first exon contained 29 SNPs with the richest allelic variations, and its meaningful mutations accounted for $30 \%$ of the total mutations. The smallest variation was found in the second exon with only 2 SNPs. SNP distributions of exons in the 20 materials are shown in Figure 2. Compared with the encoding region, the intron regions had greater variation, weaker conservation, and more insertions and deletions. A total of 142 SNPs were identified, accounting for $56.13 \%$, and every $7.30 \mathrm{bp}$ contained an average of 1 locus variation. Variation of the 4th intron was obvious, and $143 \mathrm{bp}$ contained 9 loci of single base variation, 13 loci of 2 base variation, and 15 InDels, 11 haplotypes, and 2 indel haplotypes. Besides the 8th intron, the 10th intron also had large variation, including 5 loci of single base variation, 19 loci of 2 base variation, and $50 \mathrm{InDels}, 7$ haplotypes, and 5 indel haplotypes. This indicated that the 4th and 10th introns had high variation ratio, and other introns were relatively conservative.

Diversity evaluation of the 20 encoding sequences was carried out based on the nucleotide diversity $\pi$ and nucleotide polymorphism $\theta$ (Mu et al., 2007). The results showed that the 20 loci with sequence variations presented diversified distribution, and the changing tendencies of $\pi$ and $\theta$ values were consistent (Figure 3 ). In addition, the influence of 
the natural selection on the diversity of the waxy gene was also analyzed (Figure 3). The sequences were subjected to Tajima's D test, and value of Tajima's D was -0.59255 . P value was higher than 0.01 , which was not significant, indicating that the variation ratio of waxy gene was not high on the whole.

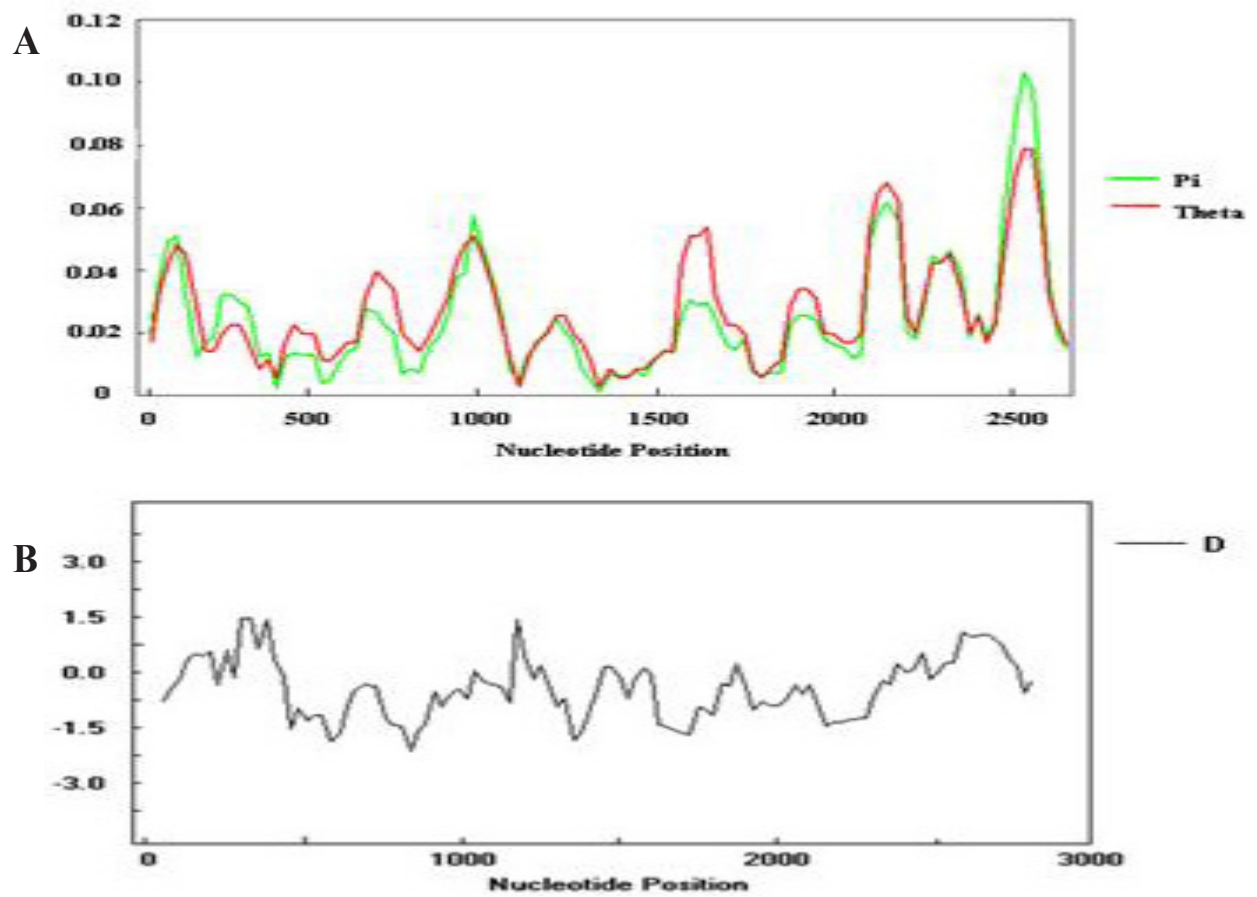

Figure 3. Diversity of the waxy gene, A. $\pi, \theta$; B. Tajima'D test.

\section{Comparative analysis of the waxy gene with close relative species}

Phylogenetic tree analysis of nucleotide sequences showed that the $W x$ gene of 20 rye materials had the closest phylogeny with $W x-A$ (EU719608) gene in wheat, followed by the $W x-D$ (EU719612) gene. The $W x$ gene was the farthest from the $W x-B$ (EU19610) gene. Sequence analysis showed that this kind of difference was mainly found in 3-5 introns, especially in the 5th intron. Difference in the 4-6 exon regions was only smaller than that of the intron region. At the same time, cDNA clustering showed that the rye cultivars were clustered into 4 types. Differences between the first type and others were mainly found in exons 1, 6, and 7. The most significant difference was the 2 meaningful mutations and 2 nonsense mutations in exon 1 and 2 nonsense mutations in exon 7 . The first type could also be divided into 2 subtypes. Differences between the subtypes were mainly the 4 base mutations of exons 4 and 5 and the meaningful mutation of locus 1087. The only Wx cDNA sequence (FJ491377) from rye in NCBI database was clustered into the second subtype. Regarding the distribution ratio of subunits in all types, Wx subunit of the first type occupied the dominant position and the proportion of the fourth type was the smallest. Sequence alignment showed that this kind of 
difference mainly existed in the 1-70 bp (exon 1 and 3-7) and 400-1370 bp regions (Figure 4). Results above suggested that rye cultivars also contained great diversity. However, this kind of diversity was only distributed in a limited number of exons, especially in exon 6 (Figures 2 and 4).

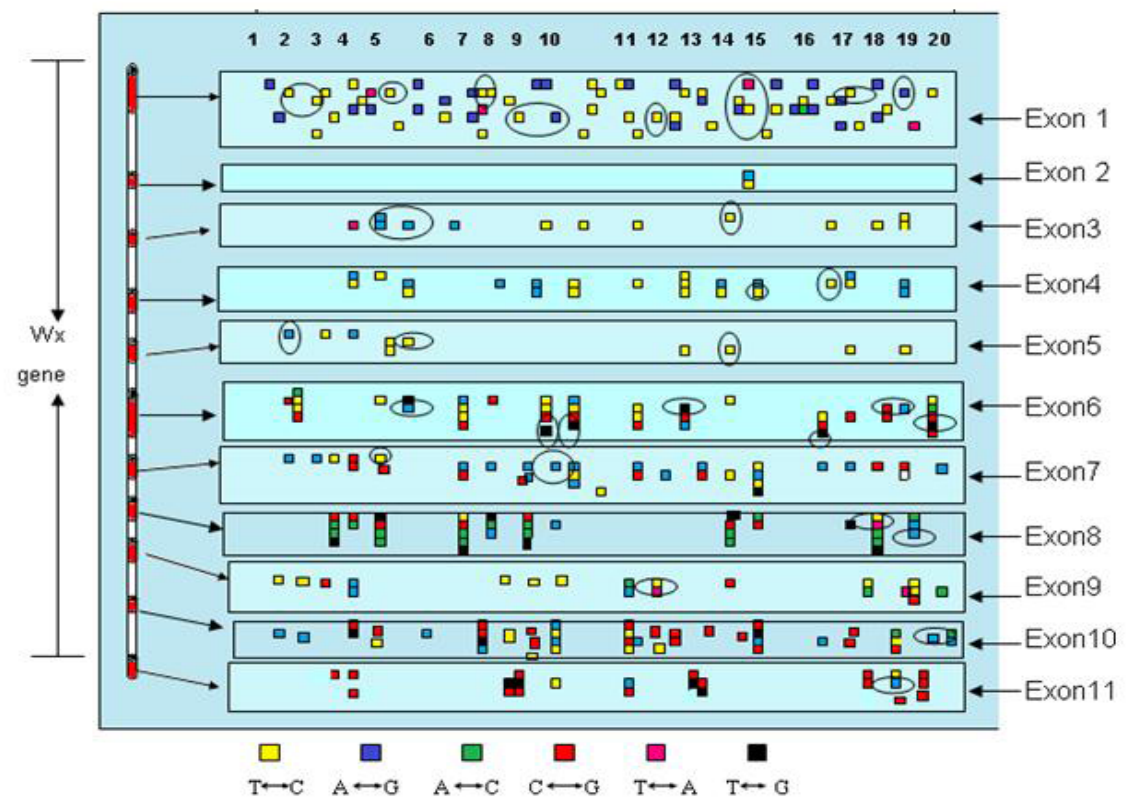

Figure 4. Sequence alignment. The left shows the gene sequence structure; the upper right is the 20 materials, and the middle indicates the SNPs of these genes. The circles represent meaningful mutations.

\section{Prediction and analysis of Waxy protein structure}

\section{Structure prediction of Waxy protein}

The full length of rye Waxy protein consisted of 604 aa. With reference to the studies by Xu et al. (2009), 1-70 aa region of Waxy protein was the signal peptide region, and mature protein $\mathrm{N}$ - and C-terminus were the non-catalytic domain (230 aa) and catalytic domain (304 aa), respectively (Figure 5). Waxy protein was UDP-glucose starch glucosyltransferase. Members in glycosyltransferase family have 4 important structural domains, including cytoplasmic domain, transmembrane domain, cervical domain, and catalytic domain in the amino end. Catalytic domain is the largest structural domain in the lumen of about 310-430 aa (the longest could contain about 720 aa) and is the most important catalytic domain for the glycosyltransferase. Similarity of rye Waxy protein was searched through EBI. Two conservative structural domains of Waxy protein $\left(\mathrm{A}_{2} \mathrm{Y}_{8} \mathrm{X}_{2}\right)$ of rice were obtained, namely, glycosyltransferases group 5 and glycosyltransferases group (Figure 5). Starting position of glycosyltransferases group 5 region was in the 84-344 aa (catalytic domain), and glycosyltransferases group 1 region was in the 399-522 aa (non-catalytic domain). Moreover, motif scanning showed that the catalytic 
domain of waxy gene in rye (glycosyltransferases group 5) was 78-339 bp, and glycosyltransferase domain (glycosyltransferases group 1) was 379-516 aa; this finding was basically consistent with the structural domain of rice. SOMP prediction of secondary structure (Figure 5 ) revealed that the vast majority was $\alpha$-helix $(\mathrm{H})$ and irregular curly $(\mathrm{C})$. The number of the former was 235 , accounting for $38.91 \%$, and the number of the latter was 79 , accounting for $13.08 \%$. Twenty-four $\beta$-turns $(\mathrm{T})$ were included with a percentage of $3.97 \%$, and 266 irregular curls $(\mathrm{C})$ were included with a percentage of $44.04 \%$. Figure 5 shows that $78-300$ aa structure was dominated by irregular curls (C) and 300-604 aa by $\alpha$-helix (H). SWISS-MODEL 3D structure prediction (Figure 5) indicated that the protein was divided into $\mathrm{A}$ and $\mathrm{B}$ domains. Domain A was the first half of the protein (about 70-350 aa), B domain was the second half of the protein (about 350-580 aa), which was dominated by $\alpha$-helix and $\beta$-pleated sheet in the middle. Functional loci of the catalytic domain were located outside domain A and the crack between domain A and domain B. The 3D structure of the 2 domains (Figure 5) revealed that the 2 conservative structural domains were different in the superstructure. Therefore, their structural domains would play diverse roles in starch synthesis. A domain was the catalytic domain, and $\mathrm{B}$ protein was the non-catalytic domain of the protein. The amino acid variations in the catalytic domain were predicted to be located in the $\alpha$-helix and $\beta$-pleated sheet of A domain and irregular curls inside the crack. The above structure was consistent with the domains of TaSSIVb (Leterrier et al., 2008) and rice Wx protein and catalytic center prediction (Li et al., 2012).



Figure 5. Prediction of Waxy protein structure (the top part) is the structural domain. *Functional sites of protein variants. The middle part is the schematic diagram of the predicted secondary structure of Waxy protein by online SOMP, in which the blue represents $\alpha$-helix, red represents $\beta$-pleated sheet, purple represents irregular curl, and green was $\beta$-turn. The third part is the prediction of $3 \mathrm{D}$ structure and the arrows indicate that the position of the structural domain. 


\section{Analysis of deduced proteins}

Similarity among the proteins encoded by the waxy gene of the 20 materials was $99.42 \%$. Variation analysis of the primary structure of protein suggested that the full sequence had 33 amino acid variations and, among them, 12 were in the peptide signal region and 21 in the mature protein region. In the non-catalytic domain (379-516 aa), 9 amino acid residues were found, and in the catalytic domain (78-339 aa), the number was 12 (Figures 2 and 5). Functional variation was mainly concentrated in the 600-1630-bp DNA, corresponding to 3-5 intron region and 3-6 exon region. Variation of amino acids caused the difference in the molecular weight of isoelectric point of the protein. The secondary structure prediction of the protein by DNAMAN (6.0 DEMO) indicated that the changes of the secondary structure were induced by the amino acid variations. Hydrophility and hydrophobicity tests showed that the properties were influenced by the variations.

\section{Starch content variation among different common ryes}

As shown in Figure 6, the percentage of total starch content in the 20 samples varied from ca. 24\% (Rye5 and Rye20) to about $61 \%$ (Rye7 and Rye 8 ), and almost $75 \%$ of the common rye samples contained starch to about $50 \%$ of the total dry seeds. The percentage of amylose and amylopectin content ranged from 4\% (Rye5, Rye17, and Rye20) to 15\% (Rye2, Rye7, and Rye 8 ) and 19\% (Rye5 and Rye20) to 48\% (Rye7 and Rye8), respectively. Ratio values of amylose-amylopectin of starch (Am:Ap) varied from 4\% (Rye2, Rye7, and Rye8) to $15 \%$ (Rye5, Rye17, and Rye20), and the relative contents of amylose were considerably lower than those of amylopectin in the corresponding rye cultivars.

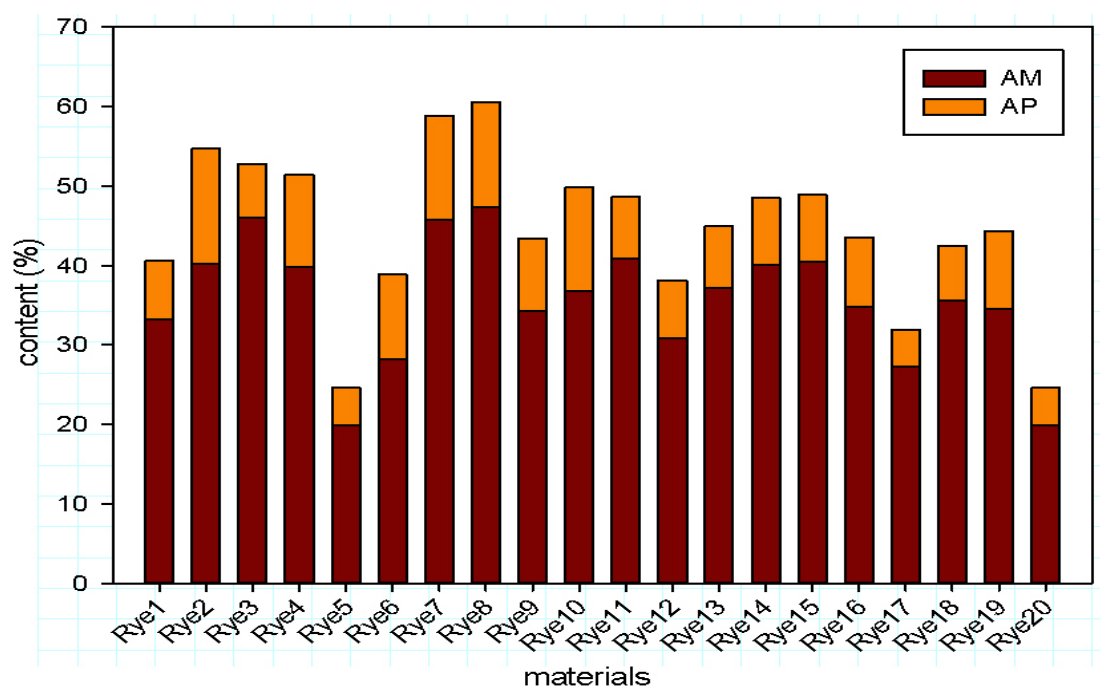

Figure 6. Starch contents variation among 20 common ryes.

\section{Waxy activity variations among common ryes}

The activity of granule-bound starch synthase I (GBSSI or Waxy) enzyme varied from 
$1.74 \mathrm{U}$ to $8.32 \mathrm{U}$ (Figure 7). Among them, the activities of Waxy enzyme in Rye2, Rye4, Rye8, and Rye10 were higher than those of any other samples, being 3-4 times higher than those in Rye1, Rye5, Rye11, Rye12, Rye14, Rye15, Rye16, and Rye19 and more than about 2 times higher than those in Rye3, Rye6, Rye7, Rye9, Rye13, Rye17, Rye18, and Rye20.

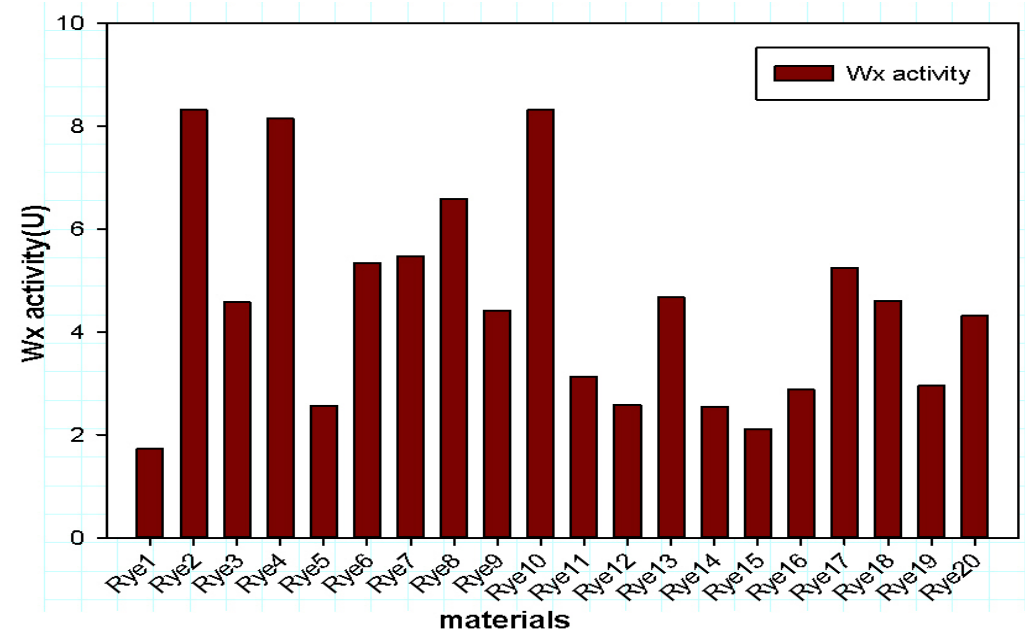

Figure 7. Wx activity variations among common ryes.

\section{RVA parameters among the rye samples}

The RVA parameters of 20 rye varieties were classified into 4 types according to the relative situation of peak viscosity and cool viscosity (Figure 8). Type 1 had a higher peak viscosity, cool viscosity, and breakdown viscosity than any other samples (Rye20 as an example). Type 2 had a higher cool viscosity and therefore a consistency viscosity than any other samples (Rye8 for example). Type 3 was similar to Type 4, except for the different peak time (Rye14 and Rye5, respectively). The details of all RVA parameters are shown in attached list 1.

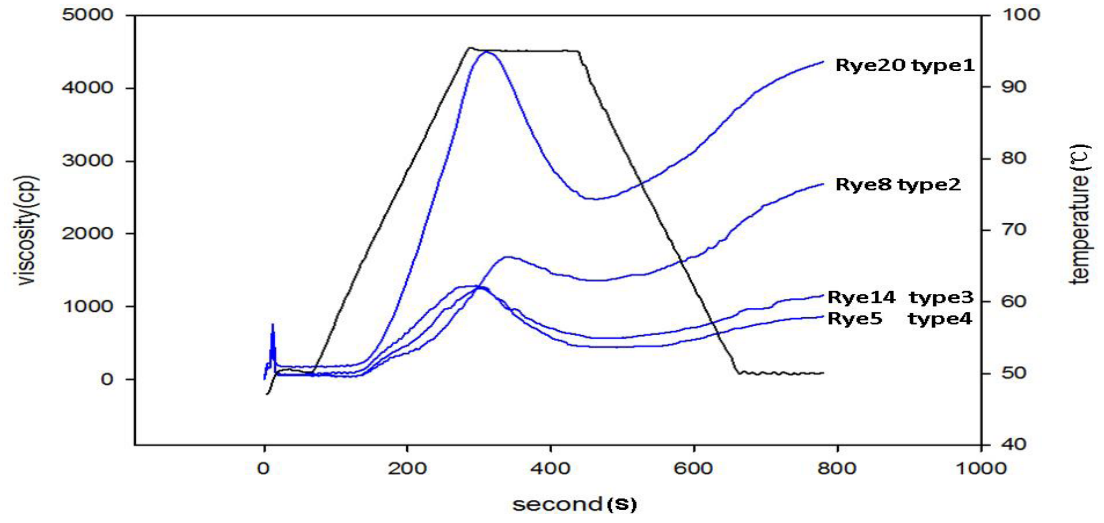

Figure 8. RVA parameters among the rye samples. 


\section{Correlation analysis}

\section{Multi-factor correlation analysis}

Multi-factor correlation analysis was performed among pasting parameters (peak viscosity, trough viscosity, final viscosity, breakdown, and setback), amylopectin content, amylose content, amylopectin/amylose ratio, and Waxy protein activity as shown in Table 2. The pasting parameters were found to be positively correlated. Trough viscosity and break-down were significantly correlated at the 0.05 level, and correlations between others were significant at the 0.01 level. Correlation between Waxy protein activity and amylose content was positive and significant at the 0.05 level, but the former was not correlated with amylopectin content or pasting parameters. Significantly negative correlation at the 0.01 level was found between amylopectin/amylose ratio and amylose content, and the former was also significantly negatively correlated with the enzyme activity at the 0.05 level. However, no direct correlations between pasting parameters (peak viscosity, trough viscosity, final viscosity, breakdown, and setback) and amylopectin/amylose contents, amylopectin/amylose ratio, and enzyme activity were identified (Table 2).

\begin{tabular}{|c|c|c|c|c|c|c|c|c|}
\hline & PV & BD & HT & FV & SB & AP & AM & EA \\
\hline $\mathrm{BD}$ & $0.932 * *$ & & & & & & & \\
\hline HT & $0.752 * *$ & $0.463^{*}$ & & & & & & \\
\hline $\mathrm{FV}$ & $0.922 * *$ & $0.738^{* *}$ & $0.916 * *$ & & & & & \\
\hline SB & $0.949 * *$ & $0.863 * *$ & $0.752 * *$ & $0.954 * *$ & & & & \\
\hline $\mathrm{AP}$ & -0.326 & -0.324 & -0.209 & -0.175 & -0.130 & & & \\
\hline AM & -0.010 & -0.099 & 0.156 & 0.138 & 0.110 & 0.199 & & \\
\hline & -0.279 & 0.403 & 0.050 & -0.072 & -0.155 & 0.285 & $0.481 *$ & \\
\hline $\mathrm{APC} / \mathrm{AMC}$ & 0.056 & 0.097 & -0.038 & -0.038 & -0.034 & 0.298 & $-0.706 * *$ & $-0.559 *$ \\
\hline
\end{tabular}

$* * \mathrm{P}<0.01, * \mathrm{P}<0.05 ; \mathrm{PV}=$ peak viscosity; $\mathrm{BD}=$ breakdown; $\mathrm{HT}=$ hold through; $\mathrm{FV}=$ final viscisity; $\mathrm{SB}=$ setback; $\mathrm{AP}=$ amylopectin content; $\mathrm{AM}=$ amylose content; $\mathrm{EA}=$ enzyme activity; $\mathrm{APC} / \mathrm{AMC}=$ amylose content /amylopectin content.

\section{Analysis with combination of SNPs in waxy}

Correlations of starch properties, including peak viscosity, trough viscosity, final viscosity, breakdown, setback, amylopectin content, amylose content, and Waxy protein activity with SNPs in the 20 materials were analyzed using the TASSEL software as shown in Table 3. Five indices of the pasting property in starch were controlled by locus 779 (amino acid residue 260 in the catalytic domain). Its correlation coefficient with the peak viscosity was 0.0034 and 0.0061 with trough viscosity, which shows a statistically significant difference $(\mathrm{P}<$ $0.01)$. Correlation with breakdown was 0.0196 , reaching the significant level $(\mathrm{P}<0.05)$. Correlations with the final viscosity and setback were 0.0571 and 0.0815 , respectively, indicating no significance $(\mathrm{P}>0.05)$. However, the contributions of locus 779 to the final viscosity and setback were still relatively high, both above $25 \%$. Enzyme activity was controlled by 2 loci, locus 421 and locus 779, which encoded the amino acid residues 141 and 260 in the catalytic domain, respectively. Correlation between locus 779 (located at the residue 260 in the catalytic domain) and enzyme activity was 0.0278 , reaching a significance level $(\mathrm{P}<0.05)$. For locus 421 , the correlation (located at residue 141 in the catalytic domain) with enzyme activity was 
0.0484, which was significant $(\mathrm{P}<0.05)$. Locus 1087 had a correlation of 0.0625 with the enzyme activity and was not significant $(\mathrm{P}>0.05)$. However, its contribution to the enzyme activity was higher than $20 \%$. Contents of amylose and amylopectin were controlled by locus 421 and locus 456 (residue 141 and residue 152 in the catalytic domain) with correlation of 0.0395 and 0.0261 , respectively $(\mathrm{P}<0.05$ ), which reached the significance level. The contribution was above $20 \%$. In view of the above analysis, loci that could control or influence the pasting properties and amylose activity were found to be located in the catalytic domain of Waxy enzyme. Amino acid 260 had the greatest influence.

Table 3. Association between plant trait and polymorphism sites.
\begin{tabular}{lccc} 
& \\
\hline Train & Position & Pvalue & Contribution (\%) \\
\hline PV & 779 & 0.0034 & 38.779 \\
BD & 779 & 0.0061 & 45.07 \\
HT & 779 & 0.0196 & 40.82 \\
FV & 779 & 0.0571 & 28.60 \\
SB & 779 & 0.0815 & 25.54 \\
AM & 421 & 0.0395 & 21.50 \\
AP & 456 & 0.0261 & 24.60 \\
& 779 & 0.0278 & 37.97 \\
EA & 421 & 0.0484 & 22.20 \\
& 1087 & 0.0625 & 20.04 \\
\hline
\end{tabular}

For abbreviations, see legend to Table 2.

\section{DISCUSSION AND CONCLUSIONS}

Previous studies underscore the importance of Waxy in starch synthesis of cereal crops (Vrinten et al., 1999; Araki et al., 2000; Miura et al., 2002). Diploid rye was used as the test material to comprehensively analyze correlations of starch content, starch synthase activity, pasting parameters, and SNPs in the waxy gene.

Multi-factor analysis indicated complex correlations of peak viscosity, trough viscosity, and final viscosity with breakdown and setback of the rye flour, and this is consistent with the finding of studies on wheat flour (Batey et al., 1997). Therefore, any of the pasting parameters can be used as an important index to measure the pasting property of wheat flour. Moreover, Waxy protein activity was found to be significantly correlated with the amylose starch content. However, activity of the Waxy protein was significantly negatively correlated with amylose content. Further, amylopectin/amylose ratio had significant negative correlation with amylose content and amylase activity. However, there were no correlations between pasting parameters and amylopectin and amylose contents and between amylopectin/amylose ratio and enzyme activity. Therefore, the pasting parameters cannot be predicted based on the enzyme activity. However, some studies showed that amylose content is positively correlated with the quality parameters of noodles (firmness, adhesiveness, resilience, etc.; Yao et al., 1999). Therefore, high-throughput Waxy protein activity test will become an important tool for the rapid identification of noodle quality.

Analysis of SNPs in the key catalytic domain of Waxy protein, starch properties, and enzyme activity indicated that the pasting parameters of starch are correlated with locus 779 in exon 6. This region is a functional domain controlling the pasting features of starch. Therefore, as the evaluation index for starch parameters, SNP in this locus can be transformed into 
the molecular marker for application. Meanwhile, the starch synthase activity and amylose content were found to be mainly controlled by locus 421 in exon 3 and locus 779 in exon 6 . Therefore, SNPs in the 2 exons can be used as important marker loci to measure the activity of an enzyme. Since the starch indices and pasting parameters belonged to complex quantitative traits, the contribution of Waxy needs detailed quantitative study. Taken together, these results suggest that amino acid 260 is extremely important and can both influence the RVA starch pasting parameters and Waxy protein activity. The 2 types of properties cannot be correlated through multi-factor analysis. Thus, the correlation that cannot be found on the phenotype level will be obtained on the molecular level. The correlation analysis also reveals an interesting phenomenon: although amino acid 363 is located in the pliable region between the catalytic domain and non-catalytic domain, it can still influence the activity of Waxy protein.

Furthermore, the Waxy coding sequence, together with its deduced proteins of rye, shares significant similarity with wheat $\mathrm{Wx}-\mathrm{A}$, and hence, the present results of rye Waxy could assist in the identification of key catalytic locus of Waxy protein in common wheat varieties and promote the understanding of genetic characteristics of this enzyme. Our finding might provide theoretical reference for functional studies on different $\mathrm{Wx}$ subunits, directional selection, and identification of molecular markers in wheat.

\section{ACKNOWLEDGMENTS}

Research supported by grants from the National Natural Science Foundation of China (\#30900896), A\&F-Cyrus Tang Variety Breeding Foundation (\#A212020912), Fundamental Research Funds for the Central Universities (\#QN2009007), and Special Capital for the Construction of a Modern Agriculture Technical System in Shaanxi province (\#NYCYTX-003).

\section{REFERENCES}

Araki E, Miura H and Sawada S (2000). Differential effects of the null alleles at the three $W x$ loci on the starch-pasting properties of wheat. Theor. Appl. Genet. 100: 1113-1120.

Batey IL, Curtin BM and Moore SA (1997). Optimization of rapid-visco analyser test conditions for predicting Asian noodle quality. Cereal Chem. 74: 497-501.

Bushuk W (2001). Rye production and uses worldwide. Cereal Foods World 2: 70-73.

Carciofi M, Blennow A, Jensen SL, Shaik SS, et al. (2012). Concerted suppression of all starch branching enzyme genes in barley produces amylose-only starch granules. BMC Plant Biol. 12: 223.

Chang J, Zhang J, Mao X, Li A, et al. (2013). Polymorphism of TaSAP1-A1 and its association with agronomic traits in wheat. Planta 237: 1495-1508.

Chebotar S, Roder MS, Korzun V, Saal B, et al. (2003). Molecular studies on genetic integrity of open-pollinating species rye (Secale cereale L.) after long-term genebank maintenance. Theor. Appl. Genet. 107: 1469-1476.

Chen YT (2010). Study on Waxy Gene Diversity in Rice From China. Academy of Agricultural Sciences Press, Beijing.

Cozzolino D, Roumeliotis S and Eglinton J (2013). Relationships between starch pasting properties, free fatty acids and amylose content in barley. Food Res. Int. 51: 444-449.

Emes MJ, Bowsher CG, Hedley C, Burrell MM, et al. (2003). Starch synthesis and carbon partitioning in developing endosperm. J. Exp. Bot. 54: 569-575.

Flipse E, Keetels CJAM, Jacobsen E and Visser RGF (1996). The dosage effect of the wild type GBSS allele is linear for GBSS activity but not for amylose content: absence of amylose has a distinct influence on the physico-chemical properties of starch. Theor. Appl. Genet. 92: 121-127.

Ghiasi K, Hoseney RC, Zeneznak K and Rogers DE (1984). Effect of Waxy barley starch and reheating on firmness of bread crumb. Cereal Chem. 61: 281-285.

Hannah LC and James M (2008). The complexities of starch biosynthesis in cereal endosperms. Curr. Opin. Biotechnol. 
19: $160-165$.

Huang XQ and Brûlé-Babel A (2010). Development of genome-specific primers for homoeologous genes in allopolyploid species: the waxy and starch synthase II genes in allohexaploid wheat (Triticum aestivum L.) as examples. BMC Res. Notes 3: 140.

James MG, Denyer K and Myers AM (2003). Starch synthesis in the cereal endosperm. Curr. Opin. Plant Biol. 6: 215-222.

Jarvis CE and Walker JRL (1993). Simultaneous, rapid, spectrophotometric determination of total starch, amylose and amylopectin. J. Sci. Food Agr. 63: 53-57.

Javed-Iqbal M and Lane-Rayburn A (1994). Stability of RAPD markers for determining cultivar specific DNA profiles in rye (Secale cereale L.). Euphytica 75: 215-220.

Klosgen RB, Gierl A, Schwarz-Sommer Z and Saedler H (1986). Molecular analysis of the waxy locus of Zea mays. Mol. Gen. Genet. 203: 237-244.

Leterrier M, Holappa LD, Broglie KE and Beckles DM (2008). Cloning, characterisation and comparative analysis of a starch synthase IV gene in wheat: functional and evolutionary implications. BMC Plant Biol. 8: 98.

Li L, Tian L, Wang TT and Jiang QG (2012). Preliminary study for the molecular mechanism of low amylose content in high-quality rice (Oryza sativa L.) variety 'Qingxiangruanjing'. J. Plant Physiol. 48: 147-155.

Madej LJ (1996). Worldwide trends in rye growing and breeding. Vortr. Pflanzenzuecht. 35: 1-6.

Mérida A, Rodriguez-Galan JM, Vincent C and Romero JM (1999). Expression of the granule-bound starch synthase I (Waxy) gene from snapdragon is developmentally and circadian clock regulated. Plant Physiol. 120: 401-410.

Miura H, Wickramasinghe MHA, Subasinghe RM, Araki E, et al. (2002). Development of near-isogenic lines of wheat carrying different null $W x$ alleles and their starch properties. Euphytica 123: 353-359.

Mu J, Awadalla P, Duan J, McGee KM, et al. (2007). Genome-wide variation and identification of vaccine targets in the Plasmodium falciparum genome. Nat. Genet. 39: 126-130.

Murai J, Taira T and Ohta D (1999). Isolation and characterization of the three Waxy genes encoding the granule-bound starch synthase in hexaploid wheat. Gene 234: 71-79.

Ragaee S and Abdel-Aal EM (2006). Pasting properties of starch and protein in selected cereals and quality of their food products. Food Chem. 95: 9-18.

Rohde W, Becker D and Salamini F (1988). Structural analysis of the waxy locus from Hordeum vulgare. Nucleic Acids Res. 16: 7185-7186.

Schierbaum F, Radosta S, Richter M and Kettlitz B (1991). Studies on rye starch properties and modification, Part I: composition and properties of rye starch granules. Starch/Strke 43: 331-339.

Song JM, Li BY, You MS, Liang RQ, et al. (2004). Molecular identification of wheat granule bound starch synthase gene polymorphism. Yi Chuan Xue Bao 31: 81-86.

Tetlow IJ, Wait R, Lu Z, Akkasaeng R, et al. (2004). Protein phosphorylation in amyloplasts regulates starch branching enzyme activity and protein-protein interactions. Plant Cell 16: 694-708.

van de Wal MH, Jacobsen E and Visser RG (2001). Multiple allelism as a control mechanism in metabolic pathways: GBSSI allelic composition affects the activity of granule-bound starch synthase I and starch composition in potato. Mol. Genet. Genomics 265: 1011-1021.

Verwimp T, Vandeputte GE, Marrant K and Delcour JA (2004). Isolation and characterisation of rye starch. J. Cereal Sci. 39: 85-90.

Vrinten P, Nakamura T and Yamamori M (1999). Molecular characterization of waxy mutations in wheat. Mol. Gen. Genet. 261: 463-471.

Wang LF and Wang YJ (2001). Comparison of protease digestion at neutral pH with alkaline steeping method for rice starch isolation. Cereal Chem. 78: 690-692.

Wang ZY, Wu ZL, Xing YY, Zheng FG, et al. (1990). Nucleotide sequence of rice waxy gene. Nucleic Acids Res. 18: 5898.

Weipert D (1997). Processing performance of rye as compared to wheat. Cereal Foods World 42: 706-712.

Xia Y, Li R, Ning Z, Bai G, et al. (2013). Single nucleotide polymorphisms in HSP17.8 and their association with agronomic traits in barley. PLoS One 8: e56816.

$\mathrm{Xu}$ J, Frick M, Laroche A, Ni ZF, et al. (2009). Isolation and characterization of the rye Waxy gene. Genome 52: 658-664.

Yamamori M and Quynh NT (2000). Differential effects of Wx-A1, -B1 and -D1 protein deficiencies on apparent amylose content and starch pasting proteins in common wheat. Theor. Appl. Genet. 100: 32-38.

Yao DN, Wang XW, Liu ZY and Liu GT (1999). Identification and Screen of Waxy Protein in Wheat. J. Agr. Biotechnol. 7: $1-10$.

Zeng M, Morris CF, Batey IL and Wrigley CW (1997). Sources of variation for starch gelatinization, pasting, and gelation properties in wheat. Cereal Chem. 74: 63-71. 